\title{
ОСНОВЫ ПЕРСОНАЛИЗИРОВАННОЙ ДИЕТОТЕРАПИИ ПРИ ОЖИРЕНИИ
}

\author{
Лапик И.А., Гаппарова К.М. \\ ФГБУН «ФИЦ питания и биотехнологии», Москва
}

Распространенность ожирения за последние десятилетия возросла до глобальных масштабов эпидемии. Основу лечения данного заболевания составляет диетотерапия. Однако в настоящее время при построении сбалансированного диетического рациона для пациентов с ожирением не учитываются данные молекулярно-генетических исследований с оценкой полиморфизма генов, принимающих участие в регуляции энергетического обмена.

ЦЕЛЬ: разработка и оценка эффективности диетотерапии у пациентов с ожирением на основе изучения полиморфизма rs9939609 гена FTO.

МАТЕРИАЛЫ И МЕТОДЫ: в исследование было включено 80 пациентов с ожирением I-III степени. Пациентам было проведено генотипирование с применением аллель-специфичной амплификации с детекцией результатов в режиме реального времени и использованием TaqMan-зондов, комплементарных полиморфным участкам ДНК. В зависимости от генотипов гена FTO пациенты с ожирением получали различную диетотерапию и были разделены на следующие группы: пациенты с генотипами T/T и A/T в течение 3 недель получали стандартную диету с пониженной калорийностью, а пациенты с генотипом A/A - персонализированную диету. Энергетическую ценность персонализированного рациона для каждого пациента определяли индивидуально, исходя из данных, полученных методом непрямой калориметрии. На фоне проводимой терапии оценивали показатели состава тела методом биоимпедансометрии. Статистическую обработку данных проводили с использованием программы SPSS Statistics

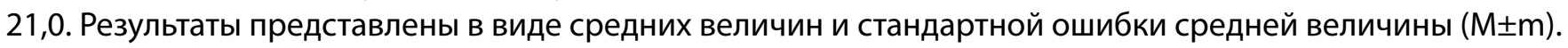
Уровень значимости считался достоверным при $p<0,05$.

PЕзУЛЬТАТЫ: по результатам исследования установлено, что у носителей генотипа A/T на фоне дие-

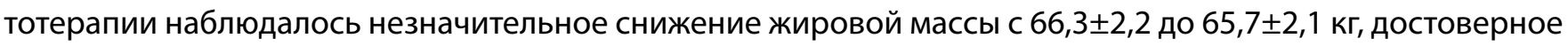

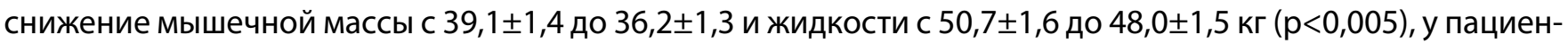
тов с генотипом A/А было отмечено достоверное снижение жировой массы тела с 87,8 $\pm 4,3$ до 82,0 33,9 кг, жидкости с $72,6 \pm 2,3$ до $68,2 \pm 1,8$ кг ( $<<0,005)$ и незначительное снижение мышечной массы с $49,4 \pm 1,9$ до 48,9 22,0 кг, а у пациентов с генотипом Т/T на фоне лечения наблюдалось достоверное снижение жировой массы тела с $36,4 \pm 1,4$ до $34,0 \pm 1,2$ кг, жидкости с $35,8 \pm 0,9$ до $34,1 \pm 0,7$ кг (p<0,005), незначительное

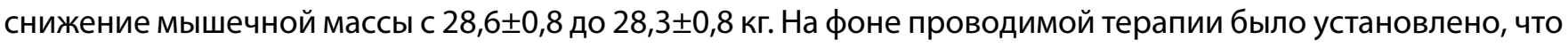
уменьшение калорийности диеты способствовало снижению массы тела у пациентов с ожирением преимущественно за счет мышечной массы у носителей генотипа A/T, а у носителей генотипов $\mathrm{T} / \mathrm{T}$ и A/A — преимущественно за счет жирового компонента, поэтому носителям мутантного аллеля А необходим подбор только персонализированной диеты.

ВЫВОдЫ: при составлении диет пациентам с ожирением рекомендовано проведение молекулярногенетических исследований, что позволит не только выявить лиц с повышенной потребностью в персонализации диетотерапии, но и повысить эффективность лечебных мероприятий при данном заболевании, предотвратив развитие его осложнений.

Научно-исследовательская работа по подготовке рукописи проведена за счет средств субсидии на выполнение государственного задания.

КЛЮЧЕВЫЕ СЛОВА: персонализачия; диетотерапия; ожирение. 